Geograficando, vol. 14, n. ${ }^{\circ}$ 1, e036, junio 2018. ISSN 2346-898X

Universidad Nacional de La Plata.

Facultad de Humanidades y Ciencias de la Educación.

Departamento de Geografía

\title{
Espacio y tiempo: articulaciones entre dimensiones virtuales y físicas
}

\section{Magdalena Lemus}

Universidad Nacional de La Plata

Instituto de Investigaciones en Humanidades y Ciencias Sociales (IdIHCS) / CONICET, Argentina

magdalenalemus.2@gmail.com

Cita sugerida: Lemus, M. (2018). Espacio y tiempo: articulaciones entre dimensiones virtuales y físicas. Geograficando 14 (1), e036. https://doi.org/10.24215/2346898Xe036

Recidido: 22 de febrero de 2018 - Aceptado: 10 de mayo de 2018 - Publicado: 31 de julio de 2018

(c) (1) Esta obra está bajo licencia Creative Commons Atribución-NoComercial-CompartirIgual 4.0 Internacional http://creativecommons.org/licenses/by-nc-sa/4.0/deed.es AR 


\section{Espacio y tiempo: articulaciones entre dimensiones virtuales y físicas.}

Time and Space: Interactions between physical and virtual dimensions

Magdalena Lemus

Universidad Nacional de La Plata - Instituto de Investigaciones en

Humanidades y Ciencias Sociales (IdIHCS) / CONICET, Argentina

magdalenalemus.2@gmail.com

\section{Resumen:}

En el artículo abordamos la apropiación de la computadora e Internet por parte de jóvenes de clases populares de la ciudad de Berisso (Prov. de Buenos Aires, Argentina). A partir de entrevistas individuales en profundidad, analizamos las percepciones del tiempo y el espacio de los jóvenes en relación al uso de Internet. Nuestros hallazgos indican que la Internet es vivida como un espacio clave en la construcción y mantenimiento de relaciones con pares, así como en la exploración de contenidos. A su vez, si bien la distinción entre dimensiones virtuales y físicas no es tajante y se viven a modo de continuos en la experiencia, no hay una reproducción lineal entre lo que ocurre en una otra.

Palabras ClaVE: Tecnologías digitales; Juventud; Apropiación; Internet.

\section{Abstract:}

In this article we study how teenagers from working class from Berisso city (Province of Buenos Aires, Argentina) use computers and the Internet. Through deep personal interviews, we analyze time and space perceptions among the youth regarding the use of the Internet. Our main findings suggest that Internet is a key place for bonding or hanging out with peers and for accessing to meaningful information. Also, we have found that even if for young people there is no clear distinction between virtual and physical spaces and they are lived as experience continuum, there is no linearity between what happens in one or the other.

KEYWORDS: Digital technologies; Youth; Appropriation; Internet.

\section{INTRODUCCIÓN}

El presente trabajo presenta los resultados de una serie de proyectos de investigación que estudiaron las articulaciones entre la desigualdad social y las tecnologías digitales (en adelante, TD) a partir de la apropiación de este tipo de tecnologías por parte de jóvenes de distintas clases sociales ${ }^{1}$. En el presente artículo ${ }^{2}$ proponemos analizar la apropiación de la computadora y de Internet por parte de jóvenes de clases populares de la ciudad de Berisso (Prov. de Buenos Aires, Argentina). En particular, indagaremos cómo perciben las dimensiones temporales y espaciales en relación al uso de Internet. A modo de hipótesis de trabajo, consideramos que el modo en que los jóvenes experimentan las dimensiones temporales y espaciales de la apropiación de Internet habilita, desde la perspectiva del espacio vivido-concebido (Lindón, Hiernaux, y Aguilar, 2006), a pensar a Internet a partir del concepto de "lugar".

A su vez, dado que la investigación fue desarrollada en el marco del Programa Conectar Igualdad ${ }^{3}$ (en adelante, PCI), consideramos que nuestro trabajo puede acrecentar la evidencia empírica sobre las implicancias del programa entre los jóvenes de sectores populares. 


\section{DEFINICIONES TEÓRICAS}

En "Etnografía virtual" Hine (2004) discute con la perspectiva que sostiene que "Internet genera interacciones sociales al margen de determinados contextos espacio-temporales", y que así "niega la geografía" (Cairncross, 1997 citado en Hine, 2004, p. 106). Según estas miradas, a través de las distintas plataformas de comunicación a las que se puede acceder en Internet, se pueden mantener relaciones entre personas en puntos distantes del planeta, sin que importe demasiado la localización geográfica o el tiempo. Al respecto, Hine sostiene que, a causa

de este tipo de afirmaciones se ha llegado a una enorme cantidad de conclusiones sobre las consecuencias sociales que podrían tener unas interacciones que trascienden las barreras del tiempo y el espacio. Muchas de estas conclusiones se han sustentado en premisas sobre las capacidades de Internet, que no tienen fundamento en la observación del papel que juegan el tiempo y el espacio en una interacción a través de este medio (2004, p. 106).

Junto a lo señalado por Hine, diversas investigaciones han puesto de relieve la necesidad de comprender las prácticas que los individuos llevan adelante en los espacios on line de forma contextualizada, por medio de análisis que integren lo que ocurre en los ámbitos físicos, off line, con los virtuales, on line (boyd ${ }^{4}$, 2014; Burrell, 2009). De esta forma, se ha tendido a desdibujar la frontera creada de antemano entre los espacios virtuales y no virtuales. Esto no ha implicado restarle especificidad a lo que tiene lugar en cada uno de estos ámbitos, sino comprenderlos de manera articulada y, en muchas ocasiones, como un continuo en la experiencia cotidiana de los individuos con las TD (boyd, 2014). En este sentido, en sus estudios sobre usos de TD por parte de jóvenes, Boyd (2014) ha puesto énfasis en abordar tanto las prácticas que se llevan a cabo on line (como usar redes sociales virtuales, navegar por la web, entre otras), como las que ocurren por fuera (como juntarse con amigos en un bar, practicar deportes, ir de compras, etc.).

Ahora bien, ¿de qué hablamos cuando decimos Internet? Como ha señalado Zukerfeld (2009), reconstruir la historia de Internet y establecer de forma concluyente qué es resulta una tarea muy compleja, no sólo por la heterogeneidad de elementos, procesos y actores que involucró -e involucra- su desarrollo, sino porque lo que consideramos actualmente como Internet está en constante cambio y movimiento. El camino hacia lo que hoy en día conocemos como Internet, es decir, la Internet comercial, comenzó hace varias décadas con objetivos y usos bastante distintos a los actuales, ya que estaba orientado al a las comunicaciones en áreas de seguridad y defensa en Estados Unidos. La web es así "una aplicación que funciona sobre Internet, es un invento muy posterior (...) y relativamente autónomo" (2009, p. 12). Zukerfeld propone pensar la arquitectura de Internet a partir de cinco niveles, estratos o capas. Si bien éstas tienen características, regulaciones y actores diferentes, todas estas instancias son necesarias para que efectivamente exista Internet: 1) Infraestructura (cables submarinos, satélites y tendidos de fibra óptica continentales); 2) hardware (servidores, módems y routers, computadoras, celulares); 3) software (por ejemplo: software para la infraestructura y el hardware, World Wide Web, navegadores, etc.); 4) contenidos (audios, textos, imágenes, etc.), y 5) Red Social (usuarios en sus distintos roles) (Zukerfeld, 2009, p. 15).

Dados los objetivos que perseguimos en este trabajo, nos concentraremos en el análisis de las apropiaciones de Internet referidas a los estratos cuatro y cinco. El nivel de los contenidos es entendido como aquella instancia con la "que interactúa todo usuario" (Zukerfeld, 2009, p. 16), a la que se va en busca de la información digital que se puede utilizar o descargar (como música, videos, textos, etc.). El último nivel, denominado Red Social remite a aquellos usuarios productores de contenidos ya sea a través de blogs, páginas web, plataformas como YouTube (Zukerfeld, 2009, p. 16). Un aspecto central de este nivel es que, de forma creciente, no se trata ya de meros usuarios individuales, sino de la cada vez más vertiginosa conformación de "colectivos digitales que son el alma de la llamada 'web 2.0' " (Zukerfeld, 2009, p. 16), como lo son las redes sociales virtuales Facebook, Twitter, Instagram, entre otras. Por lo tanto, en adelante, cuando hagamos referencia a Internet estaremos refiriéndonos solo a los dos últimos niveles. 
A su vez, para abordar el vínculo de los jóvenes con Internet recuperamos la perspectiva socioantropológica que estudia el vínculo entre la tecnología y la sociedad desde la experiencia de apropiación de los actores (Thompson, 1998), partiendo de las relaciones sociales y el contexto socioeconómico y cultural particular en el que se inscribe el uso significativo de las TIC (Winocur, 2007 y 2009). La "apropiación” es entendida como un proceso simbólico y material en el que un individuo o un grupo toma el contenido significativo de un artefacto y lo hace propio (Thompson, 1998, p. 17), otorgándole ciertos significados e incorporándolo a su vida, en el marco de sus espacios cotidianos y de sus relaciones con los otros (Winocur, 2009).

En lo relativo al abordaje de las experiencias espaciales de los sujetos y, especialmente, en lo concerniente al modo de acceder a la dimensión simbólica del espacio desde la perspectiva de los distintos actores sociales, Gorbán (2008) ha señalado la potencialidad de las marcas discursivas que pueden rastrearse en los relatos, y que nos permiten adentrarnos en "el modo en que los sujetos simbolizan el espacio vivido" (2008, p. 50). Es decir, se pueden encontrar en el lenguaje cotidiano de los sujetos referencias espaciales y temporales que dan cuenta del modo en que se experimentan y representan los distintos espacios y lugares que transitan y habitan a diario.

A su vez, desde la perspectiva del "espacio vivido - concebido", el espacio se constituye en objeto de indagación a partir "de los significados y valores que le son atribuidos" (Gumuchian, 1991, p. 9 en Lindón et al., 2006). Por lo tanto, el estudio del espacio implica indagar en las experiencias espaciales de los sujetos, entendidas éstas en su particular contexto histórico y social, y en tanto experiencias en donde se ponen en juego significados y valores particulares (Gumuchian, 1991, p. 9 citado en Lindón et al, 2006). De esta forma,

Los sentidos y significados del espacio son construidos a través de un proceso de contraste entre los elementos materiales y las representaciones, esquemas mentales, ideas e imágenes con las que los individuos se vinculan con el mundo, que por otra parte son de carácter socio-cultural (Lindónet al., 2006, p. 12).

Desde esta perspectiva, el concepto de lugar posibilita "comprender el espacio a partir de la experiencia del sujeto y con toda la carga de sentido que dicha experiencia lleva consigo" (Lindón et al., 2006, p. 12). Este abordaje tiene sus raíces en las formulaciones realizadas por Tuan (1979), quien destaca la importancia de estudiar los lugares a partir de la comprensión de los significados que las personas les han dado, ya que "los lugares encarnan las experiencias y las aspiraciones de las personas" (Tuan, 1979, p. 387). De esta forma, investigar los lugares implica estudiar también los sentimientos e ideas espaciales de los diversos individuos (Tuan, 1979, p. 388). Tuan pone también especial énfasis en el carácter histórico y cultural de las nociones de espacio y lugar al sostener que nuestra percepción del espacio y nuestro modo de construirlo, así como la manera en que esto orienta nuestros comportamientos, es variante entre las distintas culturas e individuos (Tuan, 1979, p. 389). Junto a esto, retomamos lo señalado por Bauman respecto a las diversas formas en que la distancia es procesada socialmente: "La 'distancia', lejos de ser objetiva, impersonal, física, es un producto social; su magnitud varía en función de la velocidad empleada para superarla (y en una economía monetaria, en función del coste de alcanzar esa velocidad)" (1999, p. 21).

Entonces, si retomamos las críticas de Hine (2004), al momento de analizar la apropiación de Internet es central dar cuenta del modo en que se entrelazan con las dimensiones espaciales y temporales, virtuales y no virtuales. En este sentido, si bien Internet abre la puerta, al menos potencialmente, a acceder y compartir distintos tipos de información y contenidos de forma rápida y sin mediar la presencia física, esto no habilita a desentendernos del tiempo y el espacio en tanto dimensiones estructurantes de las prácticas humanas, tanto de las físicas como de las virtuales.

\section{Metodología}

Los resultados que presentamos en este artículo se basan en el análisis de veinte entrevistas personales en profundidad (Marradi, Archenti, y Piovani, 2007) realizadas con varones y mujeres de entre $3^{\circ}$ y $5^{\circ}$ año de 
una escuela media de la ciudad de Berisso (en adelante, la Escuela). Las entrevistas se llevaron a cabo durante horario escolar (turno mañana y tarde) a lo largo del año 2012. Los encuentros tuvieron como objetivo conocer la apropiación de las TD, en especial de la computadoras e Internet de los jóvenes y sus familias, en el marco de la implementación del PCI.

La Escuela se encuentra ubicada a unas treinta cuadras del centro de Berisso y tiene una matrícula de alrededor de 400 alumnos, distribuidos de $1^{\circ}$ a $6^{\circ}$ año entre los turnos mañana y tarde. La mayor parte de los jóvenes entrevistados pertenecen a familias de sectores populares y sectores medios empobrecidos que residen en distintos barrios de la periferia de la ciudad de Berisso. Entre los padres y madres de los entrevistados se advierten recorridos educativos caracterizados principalmente por la finalización del nivel primario y del secundario, con un número significativamente menor de casos de acceso a estudios superiores. A su vez, en términos generales, los adultos presentan situaciones laborales precarias e inestables. Entre los jóvenes, más de la mitad trabaja de forma remunerada en aserraderos, bares, kioscos o almacenes, o, de manera no remunerada, en el cuidado de sobrinos y/o hermanos menores, emprendimientos familiares, cocina y limpieza en el hogar. A su vez, las trayectorias educativas de estos varones y mujeres se caracterizan por el paso por distintas escuelas secundarias, muchas veces luego de haber repetido, y también por años en los que se dejó de asistir a la escuela y luego se volvió a retomar.

\section{Condiciones de ACCESO A LAS TECNOLOGÍAS DigitALES}

En relación al acceso hogareño a la computadora e Internet antes de la implementación del PCI a partir del 2010, encontramos que más de la mitad de los entrevistados contaban con alguna computadora en su hogar (que en la mayoría de los casos era de uso compartido con el resto de la familia, principalmente con los hermanos), y, de ese grupo, casi la totalidad tenían también conexión a Internet. Quienes no tenían computadora en su hogar antes del PCI presentan una situación económica menos favorable, caracterizada principalmente por padres y madres con empleos con muy bajas remuneraciones o desempleados. Con la llegada de las notebooks a los hogares de los entrevistados el acceso a Internet creció hasta alcanzar a tres cuartos de las familias de los entrevistados. Sin embargo, cabe tener en cuenta que, si bien en los últimos años tuvo lugar un proceso de expansión de la presencia de TD en el hogar, de acuerdo con Tuñón (2013), el aumento de computadoras en el hogar ha sido mayor entre los estratos medios y altos. Algo similar ha ocurrido con el acceso a Internet, el cual si bien ha crecido significativamente en los últimos años -y aproximadamente un 17 $\%$ durante 2013 (INDEC, 2013)-, es entre los sectores de menores ingresos donde se registran los menores porcentajes de acceso (Tuñón, 2013).

Con respecto a la apropiación de la computadora e Internet, encontramos que los actores que propiciaron los primeros usos fueron principalmente amigos, hermanos o primos mayores, $\mathrm{y}$, en menor medida, adultos miembros de la familia o docentes. A su vez, prácticamente la totalidad de los entrevistados tuvo sus primeros accesos a las TD en los cíber del barrio, y algunos pocos lo hicieron en la casa de amigos o familiares; finalmente, sólo dos los jóvenes que usaron la computadora por primera vez desde su hogar. Estos primeros contactos con las TD tuvieron lugar, generalmente, a partir de los 9 o 10 años, tanto para los varones como para las mujeres. Solo tres entrevistados manifestaron haber comenzado a utilizar la computadora entre los 5 y 7 , y otros tres casos lo hicieron después de los 13 años.

En las primeras experiencias con las TD el uso se vinculaba casi exclusivamente con el entretenimiento, a través de juegos online y offline. Luego, los usos comenzaron a extenderse hacia la mensajería instantánea (Messenger en los primeros tiempos y Facebook más recientemente), búsquedas en la web sobre temas de interés (bandas de música, películas, programas de televisión, etc.), o para la realización de tareas escolares (generalmente búsquedas de información en Google y/o en Wikipedia). A partir de nuestros hallazgos podemos afirmar que, si bien la computadora e Internet no han sido un elemento ubicuo en el hogar durante los primeros años de vida de estos jóvenes, para la mayor parte el vínculo con la computadora e Internet sí 
se fue constituyendo desde la infancia y/o la pubertad, principalmente en instancias de acceso público como los cíber de su barrio, en sintonía con los hallazgos de Finquelievich y Prince (2007) que dan cuenta del valor social de los cibercafés.

Por otra parte, encontramos que más de la mitad de los varones y mujeres entrevistados constituyen la primera generación en su familia con conocimientos sobre informática e Internet. En la mayoría de los casos los padres y madres de los entrevistados no utilizaban la computadora o Internet, o recién habían comenzado sus primeras incursiones en el último tiempo, a partir de la llegada al hogar de una computadora de escritorio y/o la notebook otorgada por el PCI.

\section{PERCEPCIONES Y EXPERIENCIAS DE JÓVENES DE CLASES POPULARES SOBRE INTERNET: UN LUGAR DE CONEXIÓN}

Como hemos señalado en la sección anterior, las primeras experiencias de acceso y uso de las tecnologías digitales e Internet de los jóvenes entrevistados han tenido lugar, principalmente, fuera del propio hogar. A su vez, la mayor parte de estos jóvenes, junto a sus hermanos mayores, han sido quienes han introducido estas tecnologías e Internet en sus hogares y en la vida de sus padres y madres. En estos contextos se han forjado apropiaciones en las que la computadora e Internet, lejos de ser artefactos "naturales" dentro del ámbito hogareño, han sido elementos en cierta forma ajenos y novedosos.

A continuación, veremos cómo a partir de la llegada de la primera computadora al hogar -sea ésta la notebook otorgada por el PCI u otra- se transformaron las dinámicas de uso de estos dispositivos e Internet por parte de los jóvenes.

La posesión del dispositivo en el hogar y, más aún, la posibilidad de contar con conexión a Internet ha abierto la puerta a una amplia de variedad de experiencias en donde los ámbitos físicos y los virtuales se articulan y relacionan de forma compleja. Si bien la mayor parte de los entrevistados ya tenía experiencias de uso de la computadora e Internet fuera del hogar, especialmente en cíber barriales, el acceso hogareño habilitó nuevas modalidades de uso diversas y más intensivas. La apropiación de Internet por los jóvenes entrevistados dio lugar a heterogéneas experiencias en las que tiempo y espacio se volvieron elementos clave. En este sentido, en los relatos de los jóvenes de sectores populares entrevistados no encontramos "una sola versión de Internet"; es que, para ellos en torno a Internet se condensan múltiples percepciones y experiencias.

En primer lugar, en los relatos de los jóvenes, la apropiación de Internet significa la posibilidad de acortar distancias físicas con amigos y familiares que viven en otros barrios, ciudades o países. Así, es a través de plataformas virtuales -especialmente Facebook- que para los entrevistados emerge la posibilidad de mantener un contacto cotidiano y cercano con estas personas que se encuentran físicamente distantes:

E: ¿Sentís que tenés contactos que si no fuese por Internet los perderías?

L: Sí, por ahí sí. Si tenés algún familiar o amigo en otra provincia te conectás por Facebook.

(Lorenzo, 17 años)

En segundo lugar, Internet es también percibido y experimentado como un lugar en el que se traman relaciones y vínculos con los pares, así como un lugar en el que reside un conjunto muy amplio de conocimientos e información significativa para los jóvenes. Esto nos habilita a pensar que para los jóvenes Internet no sólo disminuye, al menos virtualmente, distancias y tiempos para el acceso a determinados contenidos, sino que también abre puertas a espacios atractivos y a personas desconocidas. De esta manera, Internet es también experimentada por algunos como una nueva instancia para conocer pares, que, aunque vivan en el mismo barrio o ciudad, no forman parte de su círculo de sociabilidad. En este sentido, a partir de la apropiación de Internet se amplían, al menos potencialmente, los ámbitos de sociabilidad de los jóvenes.

E: ¿Hay personas que contactaste por Facebook?

I: Ahí conocí a mi novia, por ejemplo. Yo estaba ahí re pancho, ella me habló, y me dijo de vernos y la vi. 


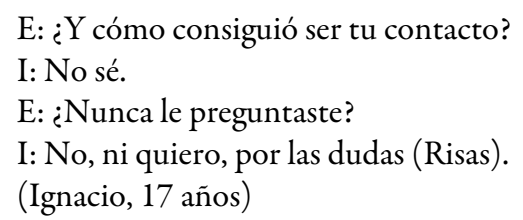

A su vez, conectarse a Internet brinda la posibilidad de moverse y desplazarse virtualmente por distintos lugares y situaciones, cuestión que resulta atractiva para muchos jóvenes:

E: Contame qué hacés a la tarde en tu casa, cuando llegás de la escuela.

Em: Chateo con amigos de la computadora, amigos virtuales que no conozco personalmente.

E: ¿Tenés muchos?

Em: Los que no conozco son como cuatrocientos, más lo que conozco, otros doscientos.

E: ¿Y chateas seguido con los que no conocés?

Em: Más o menos, a veces te hablan en inglés. Yo le mando solicitudes porque a mí me interesa lo que pasa en el otro mundo, de tanto estar acá en Argentina, ya te re acostumbrás y te da gana de saber lo que pasa afuera. Por ejemplo, yo tengo una amiga en Estados Unidos, ella me cuenta lo que pasa.

E: ¿'Te habla en inglés o castellano?

Em: Me habla en inglés, lo copio en Google traductor. Cuando le hablo yo le empiezo hablar en castellano y ella lo traduce.

(Emanuel, 17 años)

En tercer lugar, a partir del acceso a Internet, la mayor parte de los entrevistados manifestaron sentirse “actualizados" y "conectados", en contraposición a la sensación de "encierro" y "aislamiento" que dijeron sentir cuando no tenían Internet en su hogar. De esta forma, Internet es vivido como un espacio social de gran relevancia: allí se gestionan vínculos con pares, se conoce gente nueva y se accede a información y contenidos sumamente significativos, tanto en lo relativo a las cuestiones escolares como a temas y actividades de interés (por ejemplo: bandas de música, novelas, equipos de fútbol, etc.).

A: Ahora con la notebook (otorgada por el PCI) estoy más conectado. Tengo como más tiempo en mi casa con la notebook y con la otra compu. A veces nos juntamos en lo de mi abuela; ahí también la llevo y estamos con mis primos, amigos, estoy como más conectado (...) Casi todo el tiempo como jugando, también me contacto con mi grupo de amigos, como un equipo. (Adrián, 15 años)

Consideramos que el tan mencionado por los jóvenes “estar actualizado" hace referencia a poder acceder a toda aquella información, contenidos y ámbitos de sociabilidad que son significativos para ellos y sus grupos de pares, por lo que de este modo es también un "no quedarse afuera" de lo que allí, a través de Internet, se trama. Al respecto, uno de los jóvenes señalaba:

E: ¿A través del Facebook te enterás cosas que antes no te enterabas?

S: Sí, te enterás de todo.

E: ¿’Por ejemplo qué cosas?

S: No, una boludez, la otra vez se fueron a jugar al fútbol [mis amigos] y no me avisaron, yo les mande un mensajito y no me contestaron, y después me enteré por Facebook que habían arreglado, y me dejaron afuera.

(Santiago, 17 años)

En este sentido, usar Internet presupone una garantía de "actualización" que tiene dos importantes implicancias. Una de ellas es que posibilita a los jóvenes saber qué van a hacer sus amigos, a dónde salir y les permite gestionar esas relaciones. La segunda, es que "estar actualizados" implica también compartir un determinado universo de significados, por lo que la actualización es también un reaseguro de la pertenencia a las redes de sociabilidad que se traman tanto on line como off line. De acuerdo con Winocur,

la exploración del conjunto de las formas de interacción y navegación en la red de los jóvenes entrevistados, demuestra, por una parte, que todo lo que se obtiene en la red: información, entretenimiento, competencias informáticas, nuevas relaciones, se capitaliza y se valida fundamentalmente en el mundo de las relaciones persona a persona. Mucho de lo que ocurre y transcurre en Internet adquiere sentido para los jóvenes cuando pueden ejercer sus beneficios en el mundo de lo real (Winocur, 2009, p. 67). 
De esta manera, estar en Internet, recorrer su vasto territorio, implica también estar con los amigos, y pertenecer a ciertos ámbitos de sociabilidad juvenil.

Junto con la percepción de "apertura" y "libertad" que aparece asociada al acceso a Internet, también forman parte de los discursos juveniles ideas acerca del modo de experimentar el tiempo en Internet a partir de las que sostienen que "cuando están en Internet el tiempo pasa más rápido". Así, en momentos de aburrimiento dentro de la escuela o en el propio hogar, la entrada a los buscadores como Google y a las redes sociales facilita "pasar el tiempo". Al solicitarle a una de las entrevistadas que nos hablara de su experiencia con las notebooks y el acceso a Internet durante el horario escolar nos decía:

N: Por ahí, antes [de la llegada de las notebooks otorgadas por el PCI] estábamos en aula como encerrados, y ahora... no sé cómo decirlo, como te entretenés con otras cosas, y el tiempo se te pasa más rápido.

(Nadia, 17 años)

En los relatos de los varones y mujeres entrevistados se advierte continuamente cómo interactúan lo virtual y lo físico al momento de conectarse a Internet ya que, si bien muchos jóvenes han señalado que "cuando están en Internet se cuelgan y no se dan cuenta del paso del tiempo", también se evidencia cómo el modo en que se conectan se relaciona con las condiciones materiales de sus hogares: en el caso de Mercedes, en las entrevistas nos contaba de los esfuerzos para tratar de captar señal de Wi Fi del vecino, ubicando la computadora en la cocina que es donde mejor señal llega y eso, a su vez, la condiciona en el uso ya que manifestó que suele estar rodeada de sus familiares quienes le demandan que realice algunas tareas domésticas. En contraposición, parece valorar aquellos momentos en que los miembros de su familia están durmiendo y ella puede estar sola utilizando la computadora con Internet:

M: Por ahí cuando estoy con la computadora me cuesta hacer algunas cosas, levantar los platos de la mesa, me pongo como de mal humor, enojada. Me molestan cuando estoy con la computadora.

E: ¿Dónde usas la computadora?

M: En la cocina.

E: ¿Ahí agarras la señal de tu vecino?

M: Claro.

E: ¿Y estás todo el tiempo con gente?

M: Sí

E: ¿Hay algún momento que estás sola con la notebook?

M: Si, cuando por ahí no tengo clases, la mayoría está durmiendo la siesta, quedo yo sola en la cocina por lo menos.

E: ¿Y te gusta estar sola? ¿Te conectás a otras páginas?

M: Sí, escucho música, juego a los jueguitos, entro al Facebook.

(Mercedes, 17 años)

Por lo tanto, si bien los jóvenes señalan que a veces "se cuelgan" navegando por Internet, siguiendo a sus contactos en las redes sociales, ese "cuelgue" es a veces interrumpido por las demandas de atención de los docentes, o de sus padres y madres cuando están en su casa. Así, si bien en ciertos momentos los jóvenes parecieran desentenderse de aquello que los rodea cuando "están en Internet" también se advierte cómo el hogar, la escuela, o el ámbito en el que estén físicamente en ese momento en algunas ocasiones aparece tensionando los límites de lo virtual, recordándoles que estar en Internet implica también estar físicamente en algún lugar. De esta forma, el entorno físico pone de relieve la experiencia ambivalente que los atraviesa cuando están en Internet, en tanto pueden estar viajando virtualmente por lugares remotos, pero físicamente están en la cocina rodeados de su familia o en una clase en la escuela:

E: ¿Y te pasó alguna vez en la escuela, que te colgaste y había pasado mucho tiempo con la compu?

F: Sí, con el Facebook, imágenes, o frases se me pasa la hora.

E: ¿Y estabas en algún recreo?

F: No, con los profesores. Yo había entrado del recreo, estaba mirando imágenes, y seguí. Hasta que me rescato.

E: ¿Te pasa seguido eso?

F: Y a veces sí (Risas).

(Felisa, 18 años) 
El "rescatarse" al que hace alusión Felisa en su relato da cuenta de la existencia de que ciertos usos de las TD que pueden ser considerados legítimos fuera del aula o incluso dentro de este espacio pero no en momento de clase, sino en otra temporalidad, la del recreo, se vuelven inadecuados cuando suena el timbre y el docente vuelve a continuar con la clase. Consideramos que a asimilación de estas legitimidades diversas, de esta suerte de regulaciones respecto no solo del qué se puede hacer con las TD, sino también del cuándo y dónde presupone por parte de los jóvenes la internalización de un conjunto de reglas e imposiciones que muchas veces son asumidas como "naturales" por el mundo adulto.

Por otro lado, es interesante notar cómo el “estar actualizado" y “estar conectado” presente entre los jóvenes entrevistados coexiste con otras percepciones en las cuales el estar conectado a Internet implica, en cierta forma, aislarse del resto de la gente con la que uno está físicamente en ese momento. Esta experiencia es vivida por algunos jóvenes como un aspecto "positivo", en tanto sin moverse de su hogar pueden, tal como han señalado, "estar en su propio mundo". En cambio, para jóvenes como Nadia, esta "posibilidad de aislarse" es, en ciertas ocasiones, vivida como problemática, especialmente cuando ese ocurre en reuniones con amigas. Al respecto señalaba:

$\mathrm{N}$ : Porque capaz [antes de tener computadora con Internet] compartías más cosas, pasaba más tiempo juntos, ahora cada uno está en su mundo (...) cada uno está en la suya y no saben lo que pasa alrededor. (...) Cada uno está en su mundo, antes era como que todos estaban más con todos, ahora en las reuniones siempre hay uno, dos que están en la compu, están en su mundo.

(Nadia, 17 años)

Las experiencias de los jóvenes dan cuenta de un recorrido constante entre instancias de sociabilidad juvenil físicas y virtuales, en consonancia con lo señalado por Winocur (2009) en relación a la apropiación de las TD por jóvenes mexicanos de sectores populares. De acuerdo con la autora, en las rutinas cotidianas de los jóvenes se evidencia que se "desplazan entre sus realidades presenciales y virtuales con la naturalidad con que se abren y se cierran las puertas y ventanas en la vida cotidiana” (Winocur, 2009: 62). De esta forma, sostiene Winocur, "las coordenadas temporales y espaciales del mundo real se intercalan con las del mundo virtual sin que esto represente ningún conflicto de sentido para los jóvenes” (Winocur, 2009: 62). En nuestro caso, las conversaciones que se inician durante las clases o en el recreo por la mañana, continúan por la tarde en el hogar a través del chat del Facebook, para volver a ser retomadas nuevamente al otro día. En otros casos, disputas que se forjan a partir de comentarios en las redes sociales virtuales se continúan "cara a cara" en la calle, o en las aulas.

E: Vos me decías que no aceptas gente que no conocés.

A: No, sólo amigos.

E: ¿Por qué?

A: No sé, para qué tener uno más, no le hablo nada, y no ganas nada

E: ¿Borraste alguno?

A: sí, ¿y este de dónde salió? o que me bardean algunos que son loquitos. Ni los conoces ni nada y te publican en el muro, te mandan mensajes y los elimino, ni bola

E: ¿Y a tus amigos también les pasa?

A: sí, algunos sí. Y después los ves en la calle les decís algo y te niegan todo, se cagan todos.

(Adrián, 15 años)

En el relato de Adrián podemos apreciar que lo online y lo offline son experimentados como espacios que se relacionan e influencian recíprocamente. De esta forma, lo que ocurre en uno (la amenaza o pelea virtual) tiene una continuación en el espacio no virtual (por ejemplo, el ir a la calle a efectivamente pelear cuerpo a cuerpo). Sin embargo, también se advierte que las lógicas de uno y otro espacio no son necesariamente las mismas y que la amenaza virtual puede no traducirse en una pelea física, lo cual es enfatiza por Adrián cuando dice "Y después los ves en la calle les decís algo y te niegan todo". En este sentido, queda abierto el 
interrogante acerca de las características que adquieren las regulaciones dentro de los espacios on line y en cómo son experimentadas por los jóvenes.

Teniendo en cuenta el análisis realizado, consideramos que para los jóvenes entrevistados Internet es concebido y vivido como un "lugar", en donde se condensan múltiples significados, sentimientos, experiencias y en el que el tiempo y el espacio son vividas de modos particulares a través de la compleja articulación entre las instancias virtuales y las físicas. En este sentido, si bien a partir del uso de Internet los jóvenes se trasladan virtualmente por distintos ámbitos de sociabilidad, conocen gente nueva, mantienen vínculos cotidianos con amigos y familiares que viven en lugares distantes, y acceden a información sin necesidad de salir de su hogar, Internet "no se experimenta meramente como un no-espacio sino más bien como un entramado de relaciones y conexiones complejas" (Hine, 2004, p. 134).

Como hemos mostrado a partir de los relatos de los entrevistados, los jóvenes se mueven constantemente y de forma paralela entre lugares físicos, como sus hogares, la escuela, las casas de amigos y familiares o "la esquina" en su barrio, y virtuales, como el Facebook, Twitter y YouTube. Y en ese constante ir y venir de un lugar a otro a veces pareciera que el tiempo fluye rápidamente -cuando están "conectados"-y otras se ralentiza. Al respecto, Winocur ha señalado:

mientras se está conectado esta noción del tiempo desaparece porque la experiencia de la simultaneidad impone un presente continuo sobre el sentido del tiempo: estar dentro de la casa y al mismo tiempo trascender sus límites, participar de lo íntimo y de lo público, cerrar la puerta de la recámara y abrir ventanas virtuales en las recámaras de los amigos, o navegar sin rumbo definido (Winocur, 2009: 63).

A su vez, en ocasiones, la conexión a Internet habilita a los jóvenes a evadirse u olvidarse momentáneamente en dónde están físicamente -en el aula de la escuela, o en la cocina de la casa, por ejemplo- pero siempre aparecen en escena actores -como madres, padres o hermanos o los profesores-o condiciones y características del contexto, como una baja señal de Internet en el hogar, que les “recuerdan” en qué lugar están físicamente.

\section{ConcLusiones}

A lo largo del artículo analizamos los usos de la computadora e Internet por parte de jóvenes de clases populares de Berisso, poniendo especial hincapié en identificar de qué manera el tiempo y el espacio se articulan con sus experiencias de uso de TD.

En primer lugar, hallamos que el PCI ha significado una importante contribución a las condiciones de acceso a la TD para los jóvenes de clases populares, favoreciendo la contratación de Internet en buena parte de aquellos hogares que no lo tenían y proporcionando la primera computadora para casi la mitad de los hogares de los entrevistados. Además, en todos los casos, el programa ha posibilitado usos más intensivos y diversos de las TD.

En segundo lugar, nos interesa poner de relieve la existencia de una multiplicidad de formas de entender y experimentar Internet por parte de los jóvenes entrevistados. Así, usar Internet puede implicar mantenerse en contacto con amigos y familiares que viven cerca o lejos, conocer gente de lugares distantes (como otros países) pero también conocer personas de la misma ciudad con la que no se comparten espacios físicos.

En tercer lugar, entre los modos de entender a Internet por parte de los entrevistados, se destacan la potencialidad para "estar actualizado" y "estar conectado", expresiones que remiten a Internet no solo como un reservorio infinito de información y contenidos, sino especialmente como un espacio en donde se traman, gestionan y mantienen la sociabilidad y la pertenencia a los grupos de amigos.

De esta manera, entre los entrevistados, la apropiación de las TD en general, y de las redes sociales en particular, es una dimensión clave en tanto forma parte del modelalado de la experiencia juvenil contemporánea. Esto es, a través de los espacios virtuales, vividos como una suerte de continuo con los no 
virtuales, que los jóvenes continúan las interacciones que a diario tienen con pares y familiares, construyen sus gustos e identificaciones, a la que vez que gestionan sociabilidades y pertenencias.

Para finalizar, cabe destacar que, en un contexto en donde ha aumentado sustancialmente el volumen y variedad de información que circula por la web y en donde de forma creciente un conjunto de vínculos se pueden crear y recrear a través de plataformas virtuales, la apropiación de tecnologías digitales es sumamente significativa para los jóvenes de clases populares.

\section{Bibliografía}

Bauman, Z. (1999). La globalización: Consecuencias humanas. Ciudad de México. Fondode Cultura Económica. Boyd, D. (2014). It's complicated. The social lives of networked teens. New Haven, London: Yale University Press.

Burrell, J. (2009). The Field Site as a Network: A Strategy for Locating Ethnographic Research. Field Methods; 21(181), 181-199.

Finquelievich, S y Prince, A. (2007). El (involuntario) rol social de los cibercafés. Edición digital. ISBN 978-987-05-3162-3. Disponible en http://www.oei.es/tic/rolcibercafes.pdf

Gorbán, D. (2008). Algunas consideraciones sobre la desigualdad social y la simbolización del espacio. Revista Ciencias Sociales, 122 (4) 49-58.

Hine, C. (2004). Etnografia virtual. Barcelona: Editorial UOC.

Instituto Nacional de Estadísticas y Censos (INDEC) (2013). Accesos a Internet - Tercer trimestre 2013. Se consolida el crecimiento de las conexiones de banda ancha inalámbrica. Disponible en: http:// www.indec.mecon.ar/ uploads/informesdeprensa/nota_Internet_03_14.pdf [9 de marzo de 2015].

Lindón, Al; Hiernaux, D. y Aguilar, M. A. (2006). Lugares e imaginarios en la metrópolis Ciudad de México: Anthropos.

Marradi, A.; Archenti, N. y Piovani, J.I. (2007). Metodología de las Ciencias Sociales. Buenos Aires: Emecé Editores:

Thompson, J. (1998). Los media y la modernidad. Barcelona: Paidós.

Tuan, Y.F. (1979). Space and place: humanistic perspective. En S. Gale y G. Olson (Eds.). Philosophy in Geography (pp. 387-427). Dordretch: D. Reidel Publishing Company.

Tuñón, I. (2013). Hacia el pleno ejercicio de derechos en la niñez y adolescencia: propensiones, retos y desigualdades en la Argentina urbana: 2010-2012. Buenos Aires: Educa.

Winocur, R. (2007). Apropiación de Internet y la computadora en sectores populares urbanos. Versión, 19 (10),191216.

Winocur, R. (2009). Robinson Crusoe ya tiene celular. Ciudad de México: Siglo XXI.

Zukerfeld, M. (2009). Todo lo que usted siempre quiso saber sobre Internet pero nunca se atrevió a googlear. Hipertextos, 1 (2)

\section{Notas}

1 PICT 2011-1639 "Jóvenes, desigualdades y TIC. Un estudio cualitativo de las trayectorias familiares de incorporación de la computadora e Internet en el marco del Programa Conectar Igualdad en La Plata y Gran La Plata" (ANPCyTFONCYT); PIP 0756 “TIC, Juventudes y experiencias de tiempo y espacio en el marco del Programa Conectar Igualdad en La Plata y Gran La Plata” (CONICET); PPID 4003 “Jóvenes, desigualdades y TIC” (UNLP) y SIRCA II “Youth, Inequalities \& ICT” (IDRC y Nanyang Technological University of Singapur).

2 Este artículo fue escrito en el marco de la participación en la Red INCASI coordinada por el Dr. Pedro López-Roldán, proyecto de investigación europeo (Marie Skłodowska-Curie GA No 691004) que ha recibido financiamiento del programa de investigación e innovación "Horizon 2020" de la Unión Europea.

3 El Programa Conectar Igualdad se basó en un modelo 1 a 1 de incorporación de TD a la educación. Sus principales objetivos fueron disminuir la brecha digital y generar inclusión social a través de la entrega de notebooks a docentes y estudiantes de escuelas secundarias públicas, escuelas especiales e institutos de de formación docente de la Argentina. 
Junto con la entrega de las computadoras se brindó conexión a Internet a las escuelas. La distribución de las computadoras comenzó en agosto de 2010, y para marzo de 2015 se habían entregado 4.705.613. Entre fines de 2015 y mayo de 2018 fue escasa la información oficial respecto de la entrega de notebooks,la continuidad y desarrollo del PCI. El Decreto 386/2018 (28 de abril de 2018) publicado en el Boletín Oficial el 5 de mayo de 2018, suplantó el Programa Conectar Igualdad por el "Plan Aprender Conectados".

4 A lo largo del artículo el apellido boyd aparece con minúscula inicial, respetando el posicionamiento de la autora respecto de las letras capitales: http://www.danah.org/name.html (Recuperado el 12/06/2018). 